\title{
Digital Technologies in Strategic Problems and Operational Tasks for Import Substitution of Oil and Gas Facilities
}

\author{
V. Kershenbaum \\ Department of Standardization \\ Gubkin Russian State University of Oil and Gas \\ (National Research University) \\ Moscow, 119991, Russia \\ Corresponding author: tkaning@ yandex.ru \\ T. Guseva \\ Department of Standardization \\ Gubkin Russian State University of Oil and Gas \\ (National Research University) \\ Moscow, 119991, Russia \\ E-mail: tguseva14@yandex.ru \\ A. Panteleev \\ Department of Standardization \\ Gubkin Russian State University of Oil and Gas \\ (National Research University) \\ Moscow, 119991, Russia \\ E-mail: aleksandr.panteleew @ yandex.ru
}

(Received December 2, 2018; Accepted June 5, 2019)

\begin{abstract}
An algorithm for improving technical standards for the import substitution objects has been proposed in the article. The requirements of standards are considered as data arrays, the processing of which in a certain way allows developing new standards for oil and gas equipment. These standards make it possible to improve the competitiveness of Russian technology. The use of digital technologies can significantly reduce time costs, increase the objectivity of the results of document comparison and increase the reasonableness of decision-making in the development of new standards. As a methodology for comparing normative databases, a cluster analysis of the standards' requirements has been applied.
\end{abstract}

Keywords- Standards, Harmonization degree, Cluster analysis, Improvement of standards, Normative databases.

\section{The Problems of State Import Substitution Programs}

At present, the Russian Federation pays much attention to the issues of import substitution concerning the equipment and technologies of the oil and gas complex. It seems that the use of modern digital technologies for processing and managing information arrays of normative documentation of different countries and systems will undoubtedly increase the efficiency of import substitution as the most important and operational aspect of competitiveness (Kershenbaum, 2017; Bokhman et al., 2018). In the context of implementing the import substitution program, it should be noted that over 900 projects have been implemented in Russia over the past 3 years.

According to (1)-(4), the calculated harmonization degree between API and GOST R subclusters 
International Journal of Mathematical, Engineering and Management Sciences

Vol. 4, No. 5, 1208-1217, 2019

https://dx.doi.org/10.33889/IJMEMS.2019.4.5-095

is $23 \%$. More than 30 functional indicators were taken into account such as operating pressure, nofailure operating time, corrosivity class etc.

Analyzing most of the projects, the following obstacles while solving the import substitution problems have been identified (Figure 1):

(i) Lack of large-scale targeted state support for exports.

(ii) Weak stimulation of scientific and innovative activities by enterprises, insufficient awareness of the role of patenting and ensuring the protection of copyrights for exports.

(iii) Lack of highly qualified scientific, engineering and labor specialists, the training of which requires about 10 years.

(iv) Overabundance and inconsistency of documents affecting "import substitution", etc (Kershenbaum and Panteleev, 2016; Kershenbaum et al., 2018).

Cluster \#1 is devoted to the general problems of documents at various levels and their inconsistency. Conventionally, the cluster consists of regulatory documents (accepted by the Government and the ministries of the Russian Federation) and of the technical level that are documented on the standardization (Korshunov et al., 2018; Lavrova et al., 2018; Novikova et al., 2018). Within this cluster, such an important activity as national standardization deserves special attention, as bringing Russian technical standards for export and import-substituting products into compliance with international standards will allow to ensure quality improvement, access to the world market and to compete with global-scale producers (Kershenbaum et al., 2017; MalevskaiaMalevich et al., 2018).

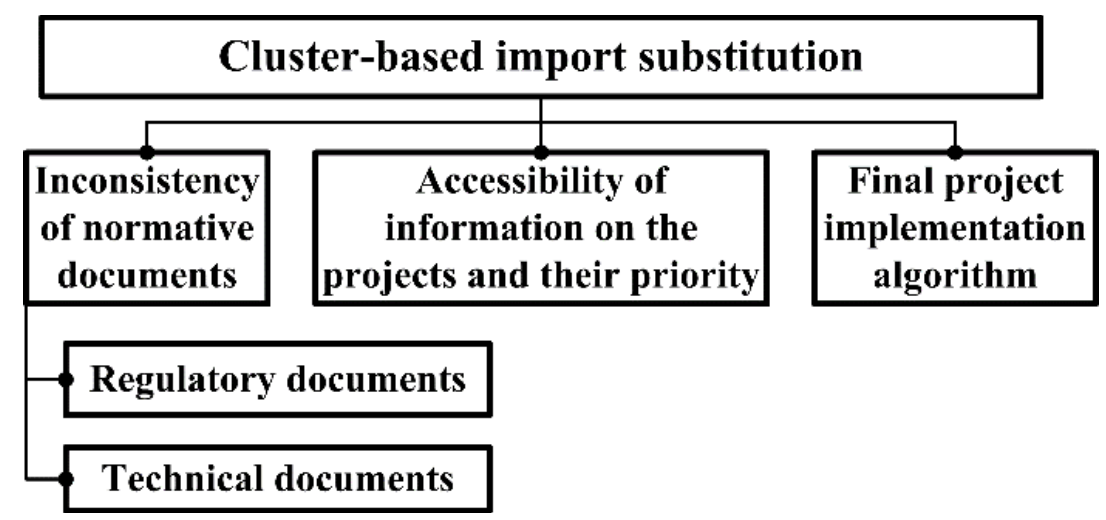

Figure 1. The problems of import substitution projects

\section{Development of Updated Standards for Import Substitution Purposes}

Due to the fact that import substitution involves determining the level of competitiveness of domestic products, technologies and their foreign counterparts, founded on benchmarking analysis of the facilities' key characteristics, comparison of regulatory bases becomes one of the most important criteria for import substitution (Guseva, 2013; Kershenbaum and Guseva, 2013; Kershenbaum and Guseva, 2016). Such a comparative analysis demonstrates the similarity and 
International Journal of Mathematical, Engineering and Management Sciences

Vol. 4, No. 5, 1208-1217, 2019

https://dx.doi.org/10.33889/IJMEMS.2019.4.5-095

differences in the regulatory requirements for the design and production of equipment, the use of various technologies in the oil and gas sector, and ultimately shows how the approaches to the creation of competitive industrial facilities in Russia and abroad are harmonized (Rumyancev, 2015; Novokshenov et al., 2018).

The proposed algorithm for working with the volume of data materials should consist of the following stages (see Figure 2):

- Analysis of foreign counterparts and patents, the purpose of which is to identify the features of products and technologies that affect their competitiveness level.

- Determinating the competitive advantages of imported objects in comparison with the characteristics of domestic products and technologies.

- Analysis of foreign standards on import substitution facilities. The goal is to determine whether the requirements of foreign standards ensure the facilities' competitiveness level.

- Determinating the harmonization degree of foreign and Russian standards. The goal is to identify the presence or absence of the requirements in Russian national documents, similar to the previously analyzed provisions of foreign standards.

- Developing or improving Russian standards for the import substitution object under study. The goal is the creation and completion of domestic standardization documents for the release of competitive facilities on their requirements (Antonova et al., 2017a).

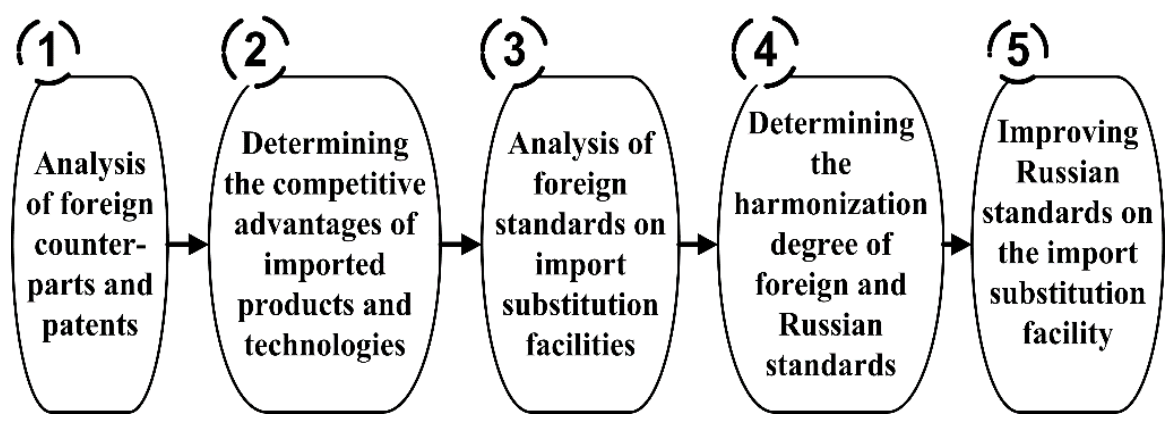

Figure 2. Stages of improving the standardization documents

\section{Data Management for Comparative Analysis of Standards}

Moreover each separate foreign and domestic standardization document should be considered as an array of data which specific processing will allow both comparing the regulatory bases of different countries and assessing the degree of their harmonization (Akhin et al., 2015; Nemov et al., 2017; Antonova et al., 2017b).

It should also be stated the following features of documents at the same level of standardization (international, national, industrial):

- the data is mainly presented in text form, however it is possible to identify key functional indicators of standardization objects that have a numerical format, 
International Journal of Mathematical, Engineering and Management Sciences

Vol. 4, No. 5, 1208-1217, 2019

https://dx.doi.org/10.33889/IJMEMS.2019.4.5-095

- data on the same object is often "scattered" across different standardization documents in the country or region under consideration (the number of documents - up to 20),

- the data has a different presentation organization of the texts of foreign and national standards, caused by the historically formed models of building the documents' sections in a particular country.

- The listed features in general complicate the harmonizating the requirements of the standards, since there is a high probability of not taking into account any important document, variously interpretating the provisions of the standards in different standardization systems (including due to incorrect translation) and in consequence of a dissimilar structure skipping the comparable requirements (Akhin et al., 2015; Klochkov et al., 2016; Klochkov et al., 2017). For the same reasons, it is extremely difficult to make the procedure of comparative analysis for standards completely automatic.

- Nevertheless, we find it possible to automate the procedure of comparing the standards' requirements by preparing them for further processing through the help of grouping into subclusters according to the principle of belonging to any standardization system, and conducting a cluster analysis of the functional parameters of the object under consideration.

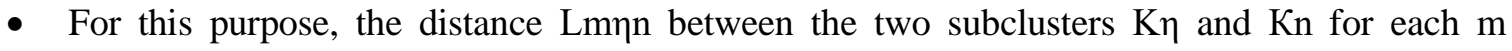
functional indicator is found as a percentage of variance, that is, the ratio of the number of inconformities Rm $\eta n$ between the subclusters to the total number of comparisons carried out Pmๆn:

$L_{m \eta n}=R_{m \eta n} / P_{m \eta n}$

Then the level of harmonization between the two subclusters Hmๆn for $\mathrm{m}$ functional indicator will be equal to:

$H_{m \eta n}=1-L_{m \eta n}$

The distance between the subclusters $\mathrm{K} \eta$ and $\mathrm{Kn}$ is found as a result of the additive convolution of the distances over all functional indicators $(\mathrm{m}=[1,2, \ldots, \mathrm{M}])$ :

$L_{\eta n}=\Sigma\left(L_{m \eta n} * g_{m}\right)$

$\mathrm{gm}$ - weight coefficient for $\mathrm{m}$ functional indicator.

Then the harmonization degree $\mathrm{H}$ between subclusters $\mathrm{K} \eta$ and $\mathrm{Kn}$ is equal to:

$H_{\eta n}=1-L_{\eta n}$

\section{Approbation of the Proposed Methodology on the Example of Oil and Gas Equipment}

The effectiveness of the developed approach has been approved at a number of oil and gas sector facilities - compressor and pumping equipment, pipe products, drilling equipment, etc. In the case study, one of the most crucial elements of drilling equipment - blowout preventer equipment (BOP) - is considered as an example (Kershenbaum and Guseva, 2016). 
International Journal of Mathematical, Engineering and Management Sciences

Vol. 4, No. 5, 1208-1217, 2019

https://dx.doi.org/10.33889/IJMEMS.2019.4.5-095

As a result of the analysis of foreign counterparts and patents for them, the following manufacturers of highly competitive BOP were identified: National Oilwell Varco (brand Shaffer), Cameron, GE Oil and Gas (ex-brand Hydril) (Guseva, 2013).

Moreover analysis of constructive, technical, and operational parameters demonstrates the following competitive advantages of foreign blowout preventer equipment:

- Subsea performance, which differs from the surface one by the special design of the BOP (with a riser and the relevant manifold), by the use of a multiplex control system (MUX system) and the ability of the BOP to hold the external pressure at depth.

- High reliability of ram and annular preventers, represented by such indicators as open/close cycles, the equivalent length of stripped pipes.

- Compactability of the blowout preventer stack due to the use of double preventers and other design solutions.

- Operational closure of sealing elements due to rapid data exchange between the BOP components through the use of SCADA technologies in control systems.

- High level of service - each of the presented manufactured provides quick replacement of seals and elastomeric lining under operating conditions, as well as timely equipment repair.

- When considering foreign standards for blowout preventer equipment, first of all it is necessary to refer to the documents of the US standardization system, because the main BOP manufacturers are located in this country. Additionally International and Norwegian documents should be analyzed as well, as their significance is recognized throughout the world.

- The review of foreign standards for blowout preventer equipment shows the following documents.

- International standards:

- ISO 13533:2001 Petroleum and natural gas industries -- Drilling and production equipment -Drill-through equipment;

- Foreign industrial and national standards:

- standards of the American Petroleum Institute:

ANSI/API SPEC 16A Specification for drill-through equipment, 4th ed., 2017,

API Std 16AR Standard for repair and remanufacture of drill-through equipment, 1st ed., 2017 ,

ANSI/API SPEC 16C Choke and kill equipment, 2nd ed., 2015,

API SPEC 16D Specification for control systems for drilling well control equipment and control systems for diverter equipment, 2nd ed., 2004,

API SPEC 16F Specification for marine drilling riser equipment, 2nd ed., 2017,

API RP 16Q Design, selection, operation, and maintenance of marine drilling riser systems, second edition, 2nd ed., 2017,

API SPEC 16R Marine drilling riser couplings, 1st ed., 1997,

API Std 53 Blowout prevention equipment systems for drilling wells, 4th ed., 2012;

- NORSOK standards:

D-001 Drilling facilities, 3rd ed., 2012,

D-010 Well integrity in drilling and well operations, 4th ed., 2013,

- DNV standards:

DNVGL-OS-E101 Drilling facilities, 2018,

DNV-RP-E101 Recertification of well control equipment for the. Norwegian continental shelf, 2017 , 
International Journal of Mathematical, Engineering and Management Sciences

Vol. 4, No. 5, 1208-1217, 2019

https://dx.doi.org/10.33889/IJMEMS.2019.4.5-095

DNV-RP-E102 Recertification of blowout preventers and well control equipment for the US outer continental shelf, 2017.

Proceeding from the presented standardization systems, it is possible to state the following 3 subclusters of foreign documents for blowout preventer equipment: API, NORSOK and DNV. Table 1 provides a summary of the imported BOP competitive examples and the impact of the subclusters' documents.

Table 1. Impact of the foreign standards requirements on competitiveness of imported BOP

\begin{tabular}{|l|l|l|}
\hline \multirow{2}{*}{ Competitive advantages } & \multicolumn{2}{|c|}{ Impact between standards and equipment } \\
\cline { 2 - 3 } Subsea performance & $\begin{array}{l}\text { Examples of imported equipment with high } \\
\text { competitiveness }\end{array}$ & Standards that provide the advantages \\
\hline $\begin{array}{l}\text { Ram preventers Quik-Loq, Compact (GE Oil and Gas), } \\
\text { TL, EVO Compact (Cameron), } \\
\text { annular preventers GX, GL, GX, Annu-Flex (GE Oil and } \\
\text { Gas), DL (Cameron), } \\
\text { MUX control system SeaPrime (GE Oil and Gas), } \\
\text { risers LoadKing, RF (Cameron) }\end{array}$ & $\begin{array}{l}\text { ISO 13533 (preventers only), } \\
\text { all the standards of API, NORSOK, DNV }\end{array}$ \\
\hline $\begin{array}{l}\text { High reliability of } \\
\text { preventers }\end{array}$ & $\begin{array}{l}\text { Annular preventer GX (GE Oil and Gas), } \\
\text { rampreventer LXT (National Oilwell Varco) }\end{array}$ & $\begin{array}{l}\text { ISO 13533, } \\
\text { API SPEC 16A }\end{array}$ \\
\hline $\begin{array}{l}\text { Compactability of the } \\
\text { blowout preventer stack }\end{array}$ & $\begin{array}{l}\text { Ram preventers Compact (GE Oil and Gas), T-81, T-82, } \\
\text { EVO Compact (Cameron), } \\
\text { annular preventer T-90, DL (Cameron) }\end{array}$ & $\begin{array}{l}\text { US Code of Federal 30CFR 250.406, all } \\
\text { the standards of API }\end{array}$ \\
\hline $\begin{array}{l}\text { Operational closure of } \\
\text { sealing elements }\end{array}$ & $\begin{array}{l}\text { Ram preventers Quik-Loq (GE Oil and Gas), EVO } \\
\text { Compact (Cameron), } \\
\text { annular preventers GL, Annu-Flex (GE Oil and Gas) }\end{array}$ & $\begin{array}{l}\text { ISO 13533, } \\
\text { API SPEC 16A, API Std 53, } \\
\text { all the standards of NORSOK, DNV }\end{array}$ \\
\hline High level of service & $\begin{array}{l}\text { Annular preventer Annu-Flex (GE Oil and Gas), } \\
\text { rampreventer LXT (National Oilwell Varco) }\end{array}$ & $\begin{array}{l}\text { ISO 13533 (preventers only), } \\
\text { all the standards of API, NORSOK, DNV }\end{array}$ \\
\hline
\end{tabular}

Based on the assessment of foreign documents subclusters, it can be assessed with high confidence that the API 16 standards define the competitive advantages of modern blowout preventer equipment.

As for the international standard, ISO 13533:2001 is an identical version of "API SPEC 16A" previous edition. Consequently, its requirements cover the preventer stack only, excluding other BOP components (manifold, control system, riser), and do not establish a comprehensive approach to standardization of BOP at the ISO level. It should be noted that in 2013 on the basis of ISO 13533 the national Russian standard GOST R ISO 13533 was adopted with the same problems as the international standard.

However, in order to determine the degree of harmonization between API subcluster and Russian documents on BOP, it is necessary to consider the relevant national standards (subcluster "GOST R”) (Kershenbaum and. Guseva, 2013):

- GOST R ISO 13533 Petroleum and natural gas industries. Drilling and production equipment. Drill-through equipment. General technical requirements,

- GOST 13862 Blowout prevention equipment. Typical schemes, basic parameters and technical 
International Journal of Mathematical, Engineering and Management Sciences

Vol. 4, No. 5, 1208-1217, 2019

https://dx.doi.org/10.33889/IJMEMS.2019.4.5-095

requirements for the design,

- GOST 12.2.115 Occupational safety standards system. Blowout preventer equipment. Safety requirements,

- GOST 27743 Blowout prevention equipment. General technical requirements.

- As the NORSOK subcluster mainly provides references to the API subcluster standards, DNV documents are developed for conformity assessment, and competitive blowout prevention equipment is produced by US manufacturers, it seems necessary to determine the level of harmonization $\mathrm{H}$ between the API and GOST R subclusters. Overview of the considered documents is shown in Figure 3.

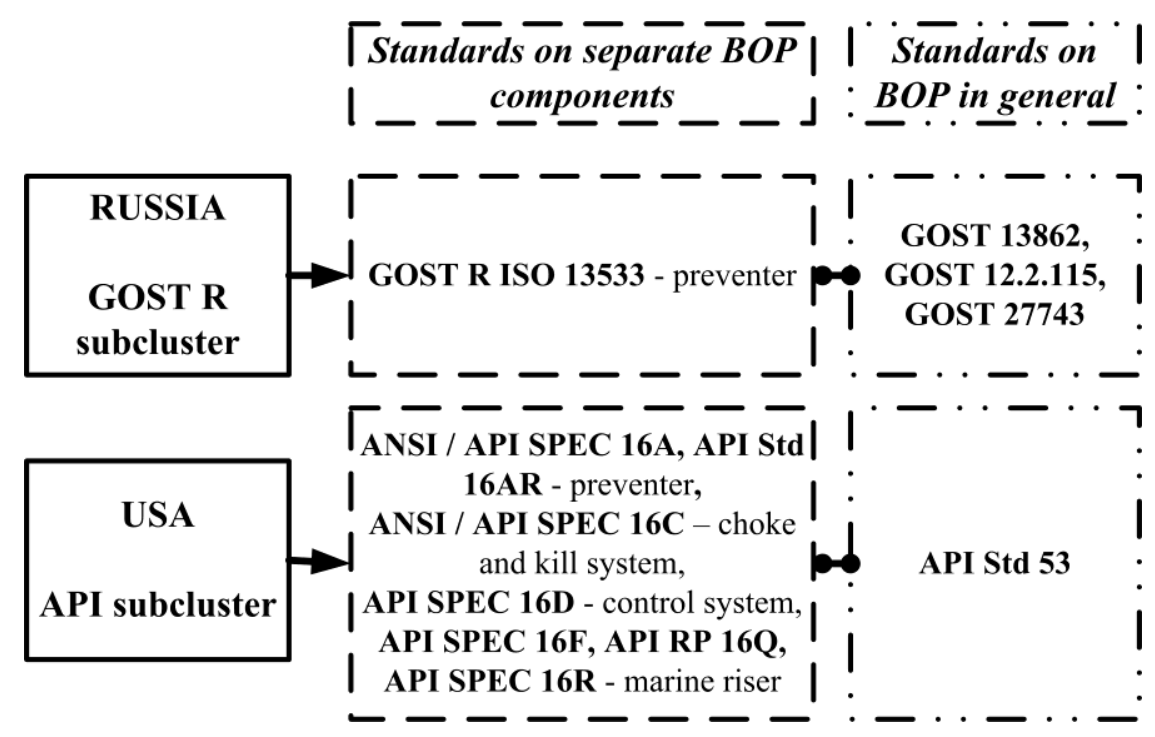

Figure 3. Foreign and Russian standards on BOP

According to (1)-(4), the calculated harmonization degree between API and GOST R subclusters is $23 \%$. More than 30 functional indicators were taken into account such as operating pressure, nofailure operating time, corrosivity class etc.

\section{Conclusion}

As a result, the cluster analysis showed that the harmonization degree between foreign and Russian documents is not high (Figure 4). GOST R standards established provisions for all BOP components are obsolete and do not meet the necessary requirements from the industry.

Indeed, the factors of insufficient competitiveness of the Russian BOP depend not only on the requirements of the national standards, but also on the economic conditions and other reasons, but it will not be possible to change the situation without developing the up-to-date complex requirements to the $\mathrm{BOP}$ components. 


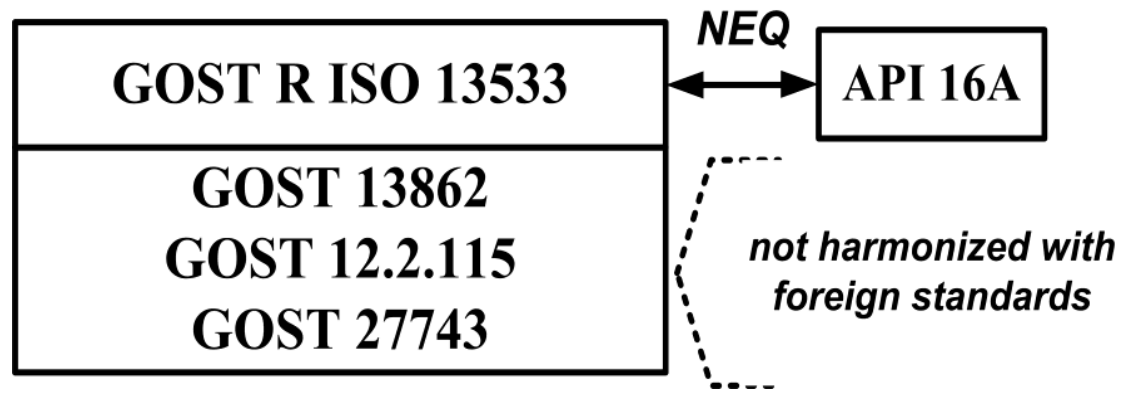

Figure 4. Harmonization degree between Russian and foreign standards

It should be emphasized that it is impossible to develop or improve Russian standardization documents on any import substitution object (in this case, blowout prevention equipment) without the principles of integrated standardization, where for each component of a technical system there are differentiated requirements to design, production, testing, maintenance and repair. Moreover, it is necessary to consider the standards as the databases, the processing of which will provide information on the degree of similarity and comparability of the standardization documents.

In conclusion, the use of digital technologies will significantly reduce time costs, increase the objectivity of the results of the documents comparison and strengthen the validity of decisionmaking when developing new standards. The use of digital technologies with integrated standardization for the automation of data processing will lead to the creation of competitive products - and this, in our opinion, should be guided by the import substitution policy.

\section{Conflict of Interest}

The authors confirm that there is no conflict of interest to declare for this publication.

\section{Acknowledgement}

The research carried out with the support of Gubkin RSU of Oil and Gas.

\section{References}

Akhin, M., Kolton, S., \& Itsykson, V. (2015). Random model sampling: making Craig interpolation work when it should not. Automatic Control and Computer Sciences, 49(7), 413-419.

Antonova, O.V., Boldyrev, Yu.Ya., Borovkov, A.I., \& Voinov, I.B., (2017a). On the development of a design procedure of the hydrodynamic characteristics of hydrogenerator thrust bearings taking into account the heat exchange. Journal of Machinery Manufacture and Reliability, 46(6), 572-578.

Antonova, O.V., Borovkov, A.I., Boldyrev, Ya.Yu., \& Voynov, I.B., (2017b). Variational problem for hydrogenerator thrust bearing. Materials Physics and Mechanics, 34(1), 97-102. 
International Journal of Mathematical, Engineering and Management Sciences

Vol. 4, No. 5, 1208-1217, 2019

https://dx.doi.org/10.33889/IJMEMS.2019.4.5-095

Bokhman, E.D., Venediktov, V.Yu., Korolev, A.N., \& Lukin, A.Ya. (2018). Digital goniometer with a twodimensional scale. Journal of Optical Technology (A Translation of Opticheskii Zhurnal), 85(5), 269274.

Guseva, T.A. (2013). Methods to improve the efficiency of standardization for oil and gas equipment. Upravleniye Kachestvom v Neftegazovom Komplekse, 2, 18-20.

Kershenbaum, V.Ya. (2017). From import-dependence - in competitiveness. Realities and myths: scientific edition. Moscow: National Institute of Oil and Gas, 2017

Kershenbaum, V.Ya., \& Guseva, T.A. (2013). A surprising look at the updated standards on oil and gas equipment. Oborudovaniye i Tekhnologii Dlya Neftegazovogo Kompleksa, 2, 4-6.

Kershenbaum, V.Ya., \& Guseva, T.A. (2016). Corporate systems of standardization and certification for improving the supply of equipment for the oil and gas industry. Oborudovaniye $i$ Tekhnologii Dlya Neftegazovogo Kompleksa, 3, 4-8.

Kershenbaum, V.Ya., \& Panteleev, A.S. (2016). The problems of standardization in the field of subsea production systems. Upravleniye Kachestvom v Neftegazovom Komplekse, 4, 34-38.

Kershenbaum, V.Ya., Panteleev, A.S., Il'in B.S. (2017). The possibility of import substitution of critical components in the example of a subsea production systems (SPS). Oborudovaniye $i$ Tekhnologii Dlya Neftegazovogo Kompleksa, 3, 4-7.

Kershenbaum, V.Y., Shmal, G.I., \& Panteleev, A.S. (2018). The main directions of standardization in the field of subsea production systems (Russian). Oil Industry Journal, 2018(2), 102-104.

Klochkov, Y.S., Didenko, N.I., Makov, K.M., Zapivahin, I.O., Ostapenko, M.S., \& Volgina, A.D. (2017, November). Employment and professional adaptation of specialists. In 2017 IEEE VI Forum Strategic Partnership of Universities and Enterprises of Hi-Tech Branches (Science. Education. Innovations)(SPUE), (pp. 162-164). IEEE.

Klochkov, Y., Gazizulina, A., \& Golovin, N. (2016, February). Assessment of organization development speed based on the analysis of standards efficiency. In 2016 Second International Symposium on Stochastic Models in Reliability Engineering, Life Science and Operations Management (SMRLO), (pp. 530-532). IEEE.

Korshunov, G.I., Lapkova, M.Y., Polyakov, S.L., \& Frolova, E.A. (2018). Models for formation and choice of variants for organizing digital electronics manufacturing. In IOP Conference Series: Materials Science and Engineering, 327(2), 022063.

Lavrova, D., Poltavtseva, M., \& Shtyrkina, A. (2018, May). Security analysis of cyber-physical systems network infrastructure. In 2018 IEEE Industrial Cyber-Physical Systems (ICPS), (pp. 818-823).

Malevskaia-Malevich, E.D., Leonov, S.A., \& Denis, Z. (2018). Methods for assessing the effectiveness of research and development. The Proceedings of the 31st International Business Information Management Association Conference, IBIMA 2018: Innovation Management and Education Excellence through Vision 2020, pp. 5620-5625.

Nemov, A., Novokshenov, A., Lagutkina, A., Sycheva, S., Mamchits, D., Borovkov, A., \& Lukyanov, V. (2017). Multiphysics engineering analysis for high field side reflectometry. Fusion Engineering and Design, 124, 501-506.

Novikova, O., Shirokova, S., Tabakova, A., \& Shadrin, A. (2018). University energy management improvement on basis of standards and digital technologies. In MATEC Web of Conferences, 170, pp. 03006. EDP Sciences.

Novokshenov A.D., Marchenko P.A., Nemov, A.S., \& Borovkov, A.I. (2018). Optimizing the support of a stellar sensor. Russian Engineering Research, 38(1), 7-12. 
International Journal of Mathematical, Engineering and Management Sciences

Vol. 4, No. 5, 1208-1217, 2019

https://dx.doi.org/10.33889/IJMEMS.2019.4.5-095

Rumyancev, I.A. (2015, February). Efficient amplification techniques for signals with high PAPR. In 2015 IEEE NW Russia Young Researchers in Electrical and Electronic Engineering Conference (EIConRusNW), (pp. 139-142). IEEE. 